\title{
ANÁLISE DOS ANÚNCIOS DA REVISTA CHANAAN
}

\author{
Júlia Sousa Azerêdo \\ Universidade Federal do Espírito Santo \\ juliazeredodi@gmail.com \\ Letícia Pedruzzi Fonseca \\ Universidade Federal do Espírito Santo \\ leticia.fonseca@ufes.br
}

Resumo: Este artigo apresenta a análise dos anúncios na revista Chanaan, com foco em seus aspectos gráficos e em sua contribuição para a composição e identidade gráfica da revista. Veiculada entre 1936 e 1939, a revista Chanaan circulou em Vitória, Espírito Santo, e representava o progresso intelectual e artístico da sociedade capixaba dos anos 1930. Colaborando com a identidade visual da revista, os anúncios foram identificados e categorizados como híbridos, classificados, tipográficos ou imagéticos, que eram compostos por fotografias, ilustrações ou quadrinhos. A maioria dos anunciantes eram do Espírito Santo, porém com frequência havia anúncios nacionais e também de outros estados. $O$ estudo tem como objetivo apresentar as análises e seus resultados com as particularidades gráficas dos anúncios. Dessa forma, pretende-se contribuir com os estudos sobre cultura material e colaborar na construção da memória gráfica capixaba.

Palavras-chave: design; memória gráfica; anúncios; revista; Espírito Santo.

\begin{abstract}
This article presents an analysis of the ads in Chanaan magazine, focusing on its graphic aspects and its contribution to the composition and the graphic identity of the magazine. Conveyed between 1936 and 1939, Chanaan magazine circulated in Vitória, Espírito Santo, and represented the intellectual and artistic capixaba society progress in the 1930's. Collaborating with the magazine visual identity, the ads were identified and categorized as hybrids, classifieds, typographical or imagistic, compounds by photos, illustrations or comics. Most advertisers were from Espírito Santo, but frequently there were national ads and also from other states. The study aims to present the analyzes and its results with the graphic particularities of the ads. Thus, we intend to contribute to the studies on material culture and to collaborate in building the capixaba graphic memory.
\end{abstract}

Keywords: design; graphic memory; ads; magazine; Espírito Santo. 


\section{INTRODUÇÃO}

Considerando a indústria gráfica como veículo de informações, com participação direta no cotidiano de uma sociedade através de impressos, são fontes valiosas: revistas, jornais, dentre outros periódicos, para construção da história do design (Leschko, 2010).

Tendo isso em vista, a presente pesquisa tem por objetivo analisar aspectos gráficos da imprensa capixaba e buscar características que ajudem a definir sua identidade. Para isso, definiu-se como objeto de estudos os anúncios da revista Chanaan, que circulou entre 1936 e 1939, em Vitória, Espírito Santo, Brasil.

Percebeu-se uma rica variação e frequência de anúncios na revista, que acabavam fazendo parte do projeto gráfico e contribuíam com a composição e identidade visual da Chanaan. Os anúncios continham diferentes produtos e composições gráficas e anunciantes de diversos lugares do país, apresentando anúncios tipográficos; imagéticos, compostos por fotografia, ilustração e quadrinho; classificados e anúncios híbridos, considerados assim por conter imagem e um longo texto.

\subsection{Chegada da imprensa no Espírito Santo e criação da Revista Chanaan}

Nas primeiras décadas do século XIX já circulavam jornais e revistas em São Paulo, Pernambuco, Bahia, Rio Grande do Sul, Minas Gerais e na Corte do Rio de Janeiro, e apenas em 1840 a imprensa chegou ao Espírito Santo, tornando possível a primeira impressão no Estado. Aires Vieira de Albuquerque Tovar lançou, junto com o Governo, o jornal O Estafeta, uma edição única com data incerta (Mattedi, 2005).

Após essa experiência isolada tem-se notícias de uma nova publicação apenas em 1849, quando Pedro Antônio de Azeredo lançou o Correio de Vitória, considerado o primeiro periódico do Estado e marco inicial da história do jornalismo capixaba. Na mesma época, foram lançados outros periódicos relacionados e financiados pelo governo e, ainda, a primeira publicação que se dizia independente, intitulada $A$ Regeneração (Mattedi, 2005). Esse atraso no estabelecimento da imprensa do Espírito Santo foi reflexo da defasagem econômica e sociocultural do Estado, que só mudou após o desenvolvimento da agricultura cafeeira (Achiamé, 2010).

A maioria dos impressos que foram surgindo tinham apoio financeiro do governo e publicavam os atos oficiais. Com a queda da Monarquia e início da República surgiu a Imprensa Oficial do Espírito Santo e foi lançado o jornal Diário da Manhã, em 1890, iniciando uma nova fase no jornalismo impresso capixaba (Mattedi, 2005).

Após a Imprensa Oficial do Espírito Santo passar por inúmeros percalços, em 1922 teve início um ano próspero com investimentos em novas oficinas e instalações no Palácio do Anchieta. Nesse período, adquiriu-se duas linotipos, máquinas de composição mecânica, "em vez de ser tipo por tipo, as ramas passaram a ser compostas por linhas inteiras, fundidas de uma vez só" (Villas-Boas, 2008, p. 99).

Contava com oficinas de obras e do jornal perfeitamente aparelhadas e amplas; seção de máquinas, dotada com as mais aperfeiçoadas; oficina de encadernação e pautação; além de sala de visitas, de espera, gabinetes do redator-chefe e do diretor comercial e sala de Redação, luxuosamente mobiliados (Mattedi, 2005, p. 41). 
As oficinas passaram a atender solicitações de trabalhos gráficos de todo o Estado (Mattedi, 2005). Nesse período, em que começaram a atender encomendas de produções gráficas, foi impressa a revista Chanaan.

A década de 1930 foi marcada por intensas rupturas políticas onde temos como ponto de partida a ascensão de Getúlio Vargas no poder e uma série de renovações na estrutura política nacional e na constituição vigente. O Espírito Santo tinha como figura marcante o capitão João Punaro Bley, interventor entre 1930 e 1943, que representava os interesses de Getúlio Vargas contra os movimentos comunistas que chegavam no Estado (Achiamé, 2010).

Bley possuía apoio do Diário da Manhã, periódico da Imprensa Oficial, para exaltar suas reformas de governo e sua autoridade estadual, logo os interventores eram comparados a ditadores do Estado (Mattedi, 2005). Contou com apoio de comerciantes locais para promover um grande desenvolvimento no Espírito Santo, como fortalecimento do orçamento público, investimentos nas estradas de rodagem, melhor infraestrutura de segurança e saúde, liquidação das dívidas do estado, estímulo das exportações e ao movimento imigratório para as regiões sul e norte do Espírito Santo (Achiamé, 2010).

Acredita-se que a revista Chanaan tenha sido idealizada por um grupo econômico, provavelmente cafeeiro, que apoiavam Bley, e sua ideologia liberal e democrata, para concorrer com a revista Vida Capichaba, que circulou entre 1923 e 1959, apesar de não serem opositoras em seu posicionamento político (Achiamé, 2010).

O capitão Bley era retratado frequentemente na Chanaan, onde apareciam suas realizações políticas, e suas fotos estampavam a presença em eventos políticos e sociais, reafirmando sua imagem política perante a sociedade capixaba.

\section{DESENVOLVIMENTO}

\subsection{Revista Chanaan}

A revista Chanaan foi publicada entre 1936 e 1939, na cidade de Vitória, Espírito Santo, sob a direção de Carlos Madeira. A revista representava o retrato da vida local durante um período de grandes transformações políticas e socioeconômicas para o estado, que era consolidado por uma comunidade oligárquica onde funcionários públicos, coronéis do café e comerciantes tinham maior relevância social (Achiamé, 2010).

Foi uma revista direcionada ao público intelectual da época, possuindo matérias redigidas em inglês, espanhol e francês. Segundo informações, contidas na própria revista, alcançou público em diversas capitais brasileiras, com circulação em Salvador, Belo Horizonte, Rio de Janeiro, São Paulo, e até fora do país.

A revista contava com correspondentes internacionais, que redigiam matérias exclusivas, e possuía espaço para poesias e literatura, matérias com personalidades nacionais e internacionais. Fazia grande uso da fotografia, que retratava não só a vida social da capital, mas também os feitos políticos. Esses feitos políticos tinham destaque na Chanaan, tendo diversas matérias dedicadas a isso. 

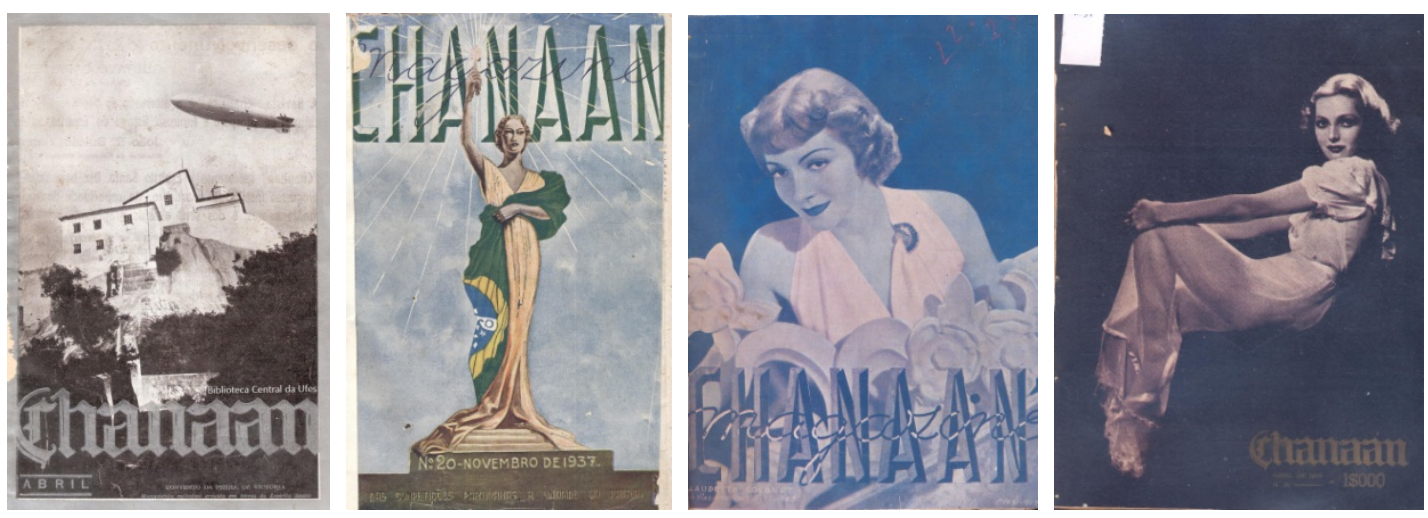

Figura 1, 2, 3 e 4 - Imagens das capas da revista Chanaan, edição 4 de 1936, edição 20 de 1937, edição 22/23 de 1938 e edição 31 de 1939.

Fonte: Elaborado pelo autor, com base na pesquisa realizada.

\subsection{Materiais e métodos utilizados na pesquisa}

O acervo da revista se encontra na Biblioteca Pública Estadual Levy Cúrcio da Rocha e na Biblioteca Central da Universidade Federal do Espírito Santo (Ufes).

O Laboratório possui o acervo digitalizado e organizado com nomenclatura padronizada por nome da revista, número de página, edição e ano: Chanaan_03_01_1936. A primeira meta da pesquisa consistiu em fazer o levantamento e recorte de todos os anúncios publicados por edição, utilizando a mesma nomenclatura do acervo, porém quando possuía mais de um anúncio por página era acrescentado um número após o ano: Chanaan _03_01_1936-1.

Após, foram realizados esboços de fichas de coleta de dados, utilizando como referência a ficha da Revista Vida Capichaba (Tonini; et all, 2010). Com a elaboração da primeira versão da ficha focada nos anúncios foram realizados diversos testes e ajustes. Todas as edições tiveram fichas preenchidas com os aspectos gráficos dos anúncios, qual era o produto, origem e sua localização na página.

A partir do preenchimento das fichas de coleta de dados, iniciou-se a tabulação das informações para a organização e sistematização dos dados, que permitiu a geração de gráficos com resultados voltados para os anúncios (Dutra; Pedruzzi, 2013).

Essa etapa da pesquisa gerou importantes resultados para a conclusão de informações gráficas e possibilitou comparações entre diferentes variáveis coletadas e sobre os anúncios em períodos diferentes da publicação da revista.

Foi realizada revisão bibliográfica que abarcou o contexto histórico no qual a revista estava inserida.

\subsection{Aspectos gráficos da Chanaan}

Foram quatro anos de publicação da revista Chanaan, entre 1936 e 1939, com trinta e duas edições publicadas, dentre elas cinco duplas. As quatro primeiras edições, tinham em média sessenta e cinco páginas; as seguintes apresentaram uma queda, chegando a ter quarenta páginas.

Era predominante o uso de papel acetinado e encadernação tipo canoa, provavelmente por ser mais simples, barato e rápido.

0 preço da revista variava entre $1 \$ 000$ e $2 \$ 000$ réis. Foi realizada uma comparação entre a variação do preço das edições e do número de páginas com o 
tipo de papel, para saber se tinha relação com o aumento do custo, mas esse impacto não foi confirmado. Ao longo da publicação o uso da imagem foi crescendo, chegando a 120 imagens na edição 20.

Também foi feita uma comparação entre o uso da imagem e o preço cobrado pela revista, e assim como a análise do tipo de papel e quantidade de páginas, não parece ter uma ligação direta, as edições com maior quantidade de imagens variavam entre os dois valores.

A mancha gráfica era composta majoritariamente por duas ou três colunas com tamanhos próximos e texto justificado. Algumas variações ocorreram em seções, matérias especiais, poesias, contos ou crônicas com alinhamento a esquerda e experimentos com colunas na diagonal.

Para Bringhurst (2005, p. 17), tipografia é um "ofício que dá forma visível e durável - e portanto existência independente - à linguagem humana". Dada a importância da tipografia para a materialização da linguagem humana e para a anatomia gráfica de uma revista, focou-se no entendimento de seu uso ao longo das edições.

As maiores frequências da quantidade de tipografias utilizadas nos textos variaram entre uma, duas e três famílias por edição. O uso da família tipográfica tinha pouca variação, as mais utilizadas eram com serifa e outra sem serifa com o terminal arredondado.

Foi produzida uma régua tipográfica em papel vegetal para medir o tamanho do corpo do texto e suas variações ao longo das edições. Aferiu-se que corpo mais frequente nos textos era $7 \mathrm{pt}$. Observou-se também que era característico da revista utilizar o corpo do texto maior nas seções fixas ou textos de destaques, como discursos de políticos da época.

Havia três formas de apresentação dos títulos de seção, dentre eles tipográfico, caligráfico e lettering. A caligrafia trata-se de "uma técnica milenar de traçar letras à mão", e o lettering é "um processo construtivo baseado no desenho, seja ele realizado por técnicas manuais ou digitais" (Finizola, 2010, p. 36 e 38). O mais utilizado era o lettering, com 110 versões de títulos diferentes e exclusivas, o que conferia muita personalidade às páginas da revista.

Era comum encontrar as assinaturas dos autores das seções e matérias. 0 tipo de assinatura mais frequente nas edições eram as tipográficas, totalizando 104 dentre todas as edições. O tamanho do corpo mais frequente era $7 \mathrm{pt}$, chegando a variar entre 10pt, 12pt e 14pt em algumas edições. O posicionamento das assinaturas mais frequente era no rodapé da página, seguido da assinatura com o título.

As legendas variavam entre base tipográfica e caligráfica. Havia uma grande variação no uso de tipografia, porém a mais utilizada era sem serifa e com terminal arredondado e regular. Assim como no corpo do texto, o tamanho do corpo da legenda mais utilizado era $7 \mathrm{pt}$, sendo encontrado também tamanhos variando entre $8 p t$ e $11 p t$. Em fotomontagens e matérias sobre políticos e a sociedade da época a legenda era maior com 9pt ou acima disso, a maior chegando a $11 \mathrm{pt}$.

\subsection{Anúncios da Chanaan}

Os anúncios publicados na revista Chanaan eram frequentes e faziam parte de sua identidade visual. 
A revista contou com quatro diretores de publicidade ao logo de sua publicação, Antônio R. Balbi, Geraldino Drummond, Wilson Laranja e Elemer Toporcz. Os diretores mais presentes nas edições foram Balbi, à frente de 17 edições, sendo 3 em parceria com Toporcz, e Drummond em 10 edições.

A maioria dos anunciantes era de empresas capixabas, totalizando $68,4 \%$ dos anúncios presentes na revista, $10,8 \%$ eram nacionais, $11 \%$ desconhecidos e $6,7 \%$ do Rio de Janeiro, os demais anúncios eram de São Paulo ou de outros estados como Bahia. Os anunciantes nacionais podem ser encontrados ainda nos dias atuais, como Colgate, Palmolive e Granado.

Em 1936, foi identificada a maior quantidade de anúncios do Espírito Santo, 528 dentre todas as edições do ano. No segundo ano, a quantidade de anúncios caiu para menos da metade do primeiro, com 235.

Para melhor análise, os anúncios foram divididos entre tipográficos, imagéticos, classificados e híbridos, que eram anúncios que possuíam imagem, porém o foco era um texto. Os anúncios foram analisados individualmente, pois havia anunciantes que no início da publicação da Chanaan apresentavam o anúncio tipográfico e ao longo da revista foi evoluindo, inserindo mais recursos gráficos e adquirindo imagem, tornando-se assim imagético.

Até a nona edição da revista, os anúncios tipográficos eram maioria, a partir de então os anúncios imagéticos se tornaram predominantes, com exceção das edições 27 e 36 .

Os classificados variavam a ocupação entre uma e duas páginas, normalmente estavam presentes na terceira capa, e algumas edições não possuíam. Já os anúncios híbridos geralmente apareceriam apenas uma vez em cada edição.

No total das edições analisadas foram contabilizados 511 anúncios tipográficos e 477 imagéticos.

\subsection{Anúncios tipográficos}

Os anúncios tipográficos tinham frequentemente bordas como apelo visual, que na análise foram divididas entre: simples, ornamentadas ou ausentes.

Vale ressaltar que a borda era considerada simples por usar apenas o fio, porém eram realizadas composições com os fios; já as bordas ornamentadas eram formadas por elementos como círculos, triângulos, tracejados com " $x$ " entre os traços, dentre outros. Se observados rapidamente, os anúncios sem bordas pareciam pertencer ao texto ou algum outro tipo de anúncio, como por exemplo, no caso da aguardente, cujo anúncio era somente a frase "O Engenho Araçatiba é o que produz a melhor Aguardente do Estado", 1936, edição 1, localizado no rodapé da página.

Até a sétima edição variava a frequência entre ter borda simples ou ornamentada, após, a simples se tornou mais frequente, e os anúncios sem bordas foram mais presentes nas três primeiras edições.

A maioria dos anúncios utilizava duas famílias tipográficas em suas composições, seguido por três famílias e depois apenas uma. Em algumas edições houve anúncio com quatro famílias, mas não era frequente.

Além de tipografia, os anúncios contavam com a presença de lettering e caligrafia em suas composições, sendo o lettering mais frequente, com 31 anúncios na segunda edição fazendo o seu uso. 
A ocupação dos anúncios tipográficos na página variava entre uma, duas ou três colunas, rodapé, cabeçalho, página inteira ou meia página. Os mais frequentes eram em uma coluna e no rodapé.
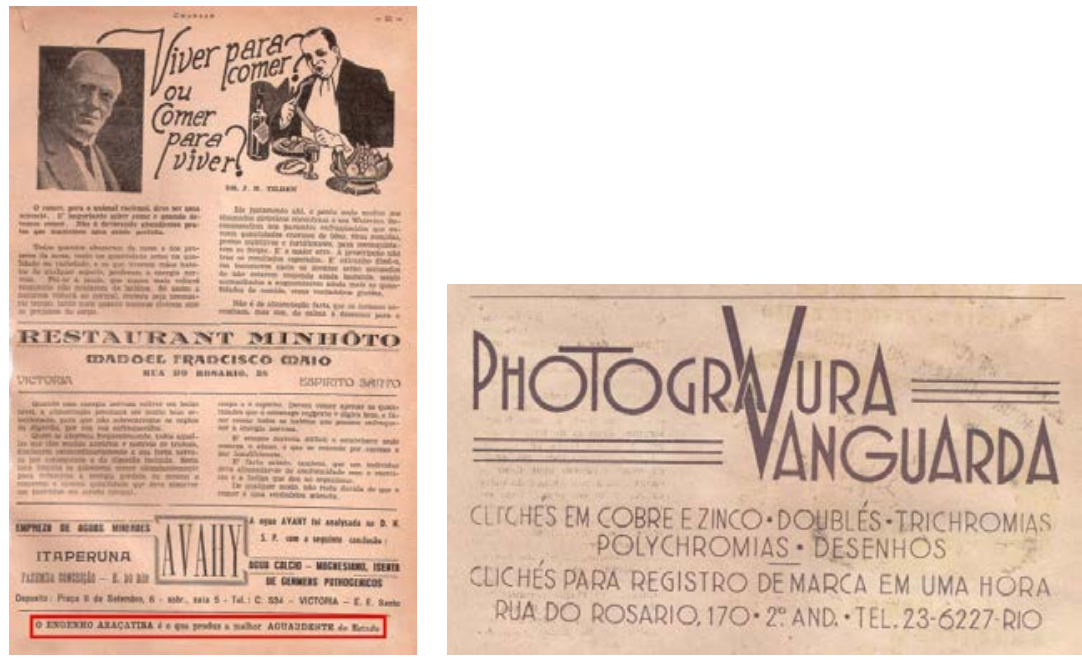

Figuras 5 e 6 - Imagem 5, onde está marcado de vermelho, é o posicionamento de um anúncio tipográfico sem borda, logo abaixo de outro, que se olhado rapidamente não pode ser identificado, página 53, edição 1,1936 . Imagem 6 , mais um exemplo de anúncio tipográfico sem borda, página 13 , edição 35, 1939.

Fonte: Elaborado pelo autor, com base na pesquisa realizada.
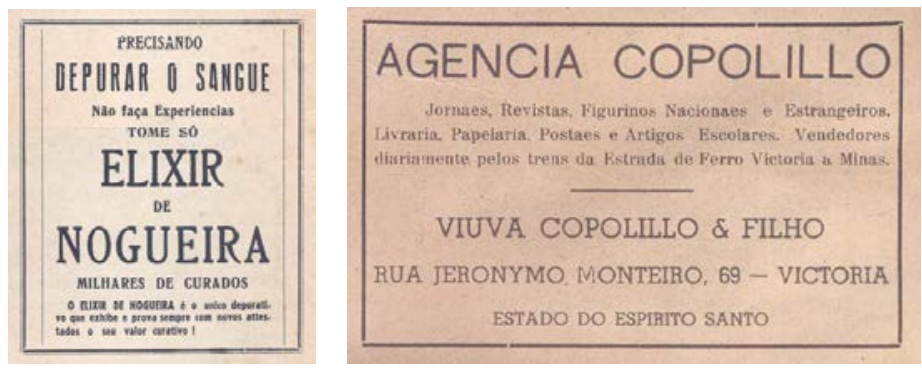

Figuras 7 e 8 - Imagens de anúncios tipográficos com borda simples, a primeira um exemplo de borda simples, porém composta por várias delas, página 31, edição 31, 1939 e página 5, edição 35, 1939, respectivamente.

Fonte: Elaborado pelo autor, com base na pesquisa realizada.
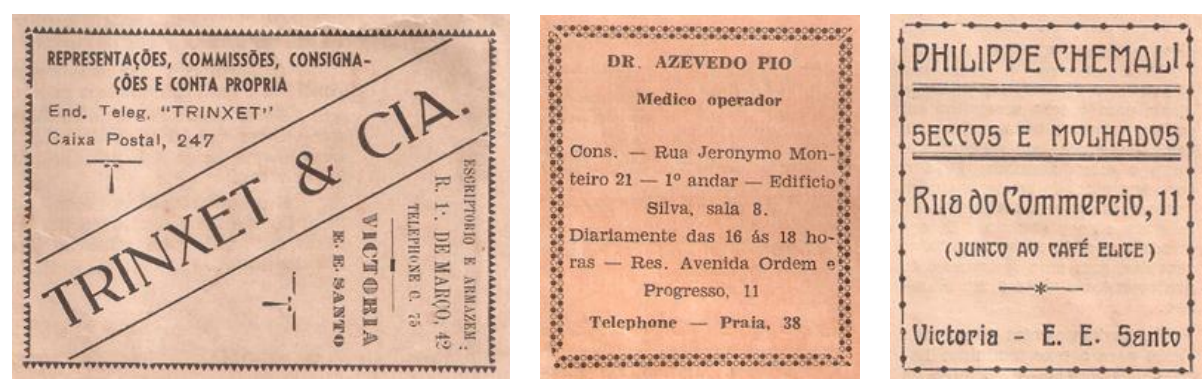

Figuras 8, 9 e 10 - Imagens de anúncios tipográficos com bordas ornamentadas, página 4, edição 1, 1936, página 20, edição 1, 1936 e página 51, edição 4, 1936.

Fonte: Elaborado pelo autor, com base na pesquisa realizada. 


\subsection{Anúncios imagéticos}

Os anúncios imagéticos variavam entre ilustração pictórica, fotografia, quadrinhos e outros (que normalmente era uma mistura de ilustração com fotografia). As ilustrações pictóricas eram mais frequentes com $80 \%$ dos anúncios, em seguida vinha a fotografia com $9,5 \%$, outros com $7 \%$ e em algumas edições possuíam anúncios em quadrinhos.

Até a edição 23, a composição dos anúncios imagéticos era feita predominantemente com duas famílias tipográficas, nas edições posteriores mudou para o uso de apenas uma família.

O uso de caligrafia e lettering nos anúncios imagéticos foi maior que os tipográficos, sendo o lettering mais utilizado.

Os anúncios imagéticos ocupavam com maior frequência uma e duas colunas, e a partir da décima terceira edição se tornou comum esses anúncios ocuparem a página inteira.
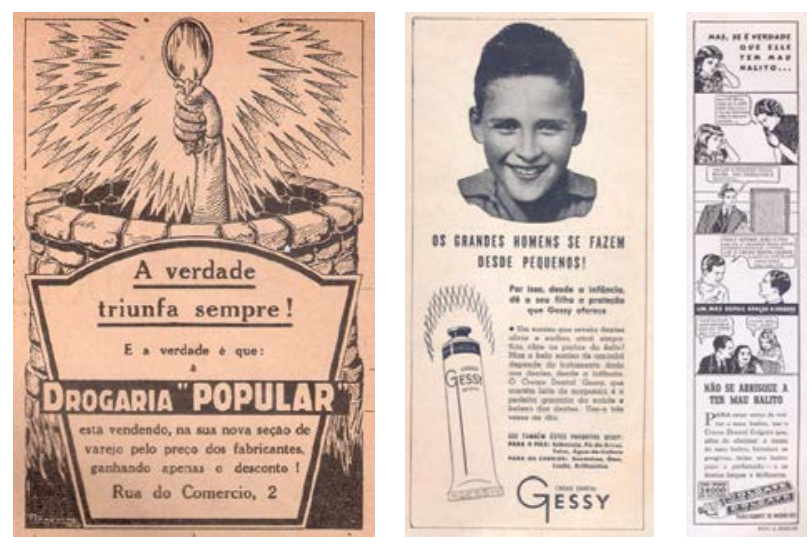

Figuras 11, 12 e 13 - Anúncios imagéticos, ilustração pictórica, fotografia e quadrinho, página 15, edição 1, 1936, página 35, edição 29, 1939 e página 15, edição 24, 1938, respectivamente.

Fonte: Elaborado pelo autor, com base na pesquisa realizada.
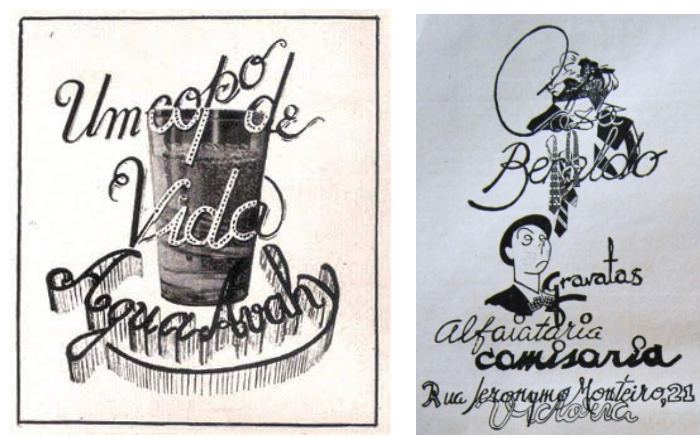

Figuras 14 e 15 - Anúncios imagéticos fazendo uso de caligrafia, página 58, edição 11/12, 1936 e página 2, edição 17, 1937 respectivamente.

Fonte: Elaborado pelo autor, com base na pesquisa realizada. 

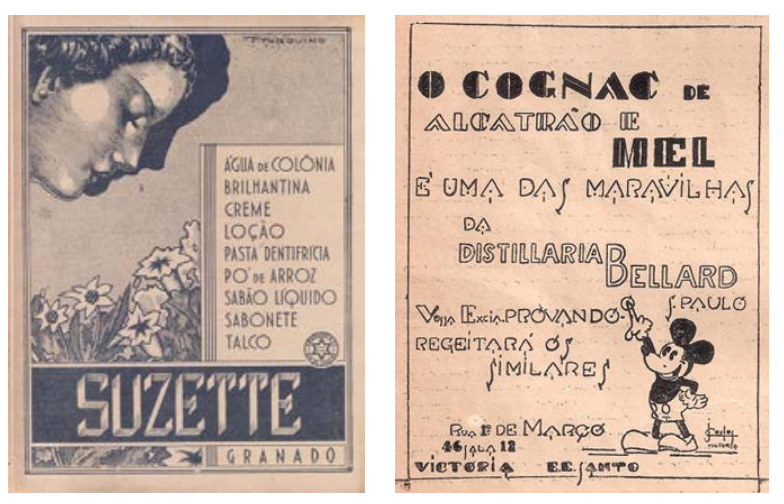

Figuras 16 e 17 - Anúncios imagéticos fazendo uso de lettering, página 8, edição 22/23, 1938 e página 50, edição 2, 1936 respectivamente.

Fonte: Elaborado pelo autor, com base na pesquisa realizada.

\subsection{Anúncios híbridos}

Não eram todas as edições que possuíam anúncios híbridos, as que tinham contabilizavam apenas um anúncio, e, a única edição que publicou dois foi a n. 34 .

As famílias tipográficas variaram entre uma a quatro diferentes por anúncio.

A maioria dos anúncios híbridos ocupou página inteira e os demais ficaram entre uma coluna ou meia página. O tipo de imagem presente no anúncio variava entre ilustração pictórica e fotografia.

Era comum esse tipo de anúncio ser ligado à saúde e ter uma explicação sobre o efeito que proporcionava, como o hormônio feminino Ovariuteran com o trecho:

Hormonios são o principio ativo de certos orgãos, o qual age no organismo mantendo a normalidade de seu funcionamento, e, portanto, a saude. Faltando um hormonio apparece logo a perturbação, a doença. Assim por exemplo, o ovario é um órgão importantíssimo para a saude das senhoras. Qualquer deficiencia desse orgão traz logo os disturbios que tanto fazem soffrer as mulheres: atrazos, colicas, hemorragias, nervosismo, etc. Desde que doente, tome, porém, um medicamento contendo o hormonio, a saude volta como por encanto (Chanaan, 1936, edição 09, p.7).

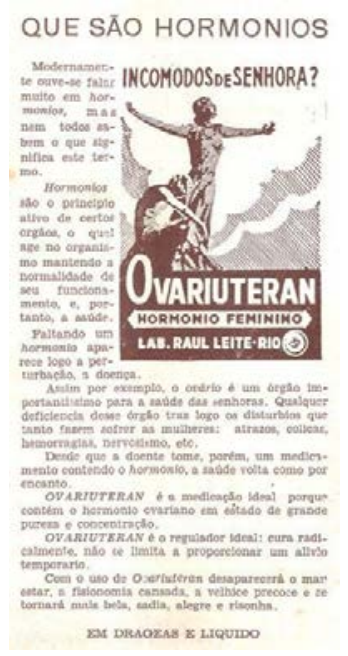

Figura 20 - Anúncio híbrido, considerado assim por conter além da imagem um longo texto, página 7, edição 9, 1936.

Fonte: Elaborado pelo autor, com base na pesquisa realizada. 


\subsection{Classificados}

Até a quarta edição a quantidade de classificados era de 34 anúncios, após isso começou a reduzir, tendo entre 17 e 14. Dentre todas as edições, 8 não tiveram classificados publicados. Os anúncios variavam sua ocupação entre a segunda e terceira capa.

Houve pouca variação tipográfica nos classificados. Até a vigésima quarta edição, predominava o uso de uma família tipográfica, a partir da trigésima edição o uso de duas famílias se tornou mais frequente.

Os anunciantes que predominavam nos classificados eram médicos, clínicas e advogados.
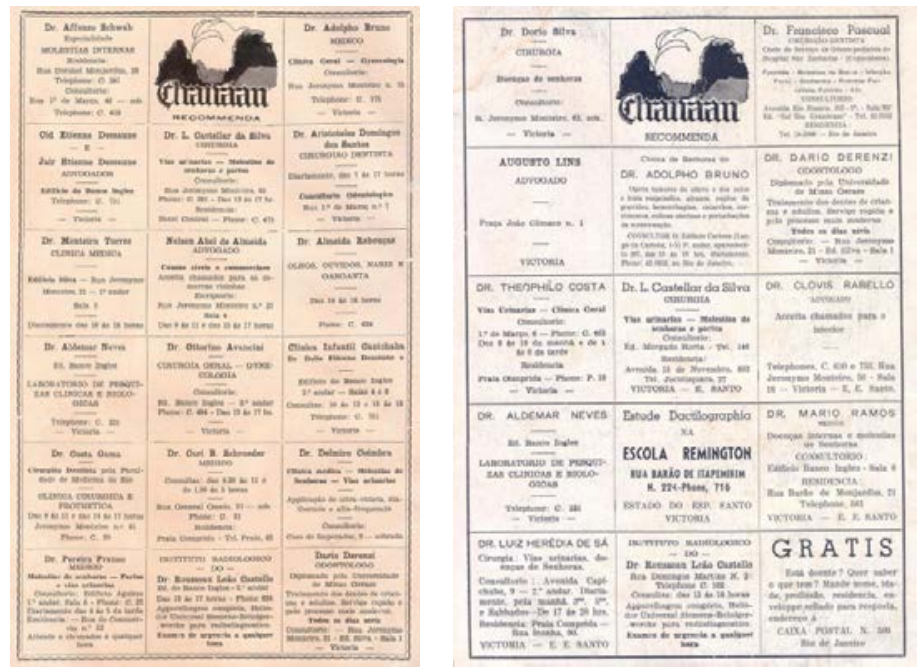

Figuras 18 e 19 - Classificados, que no início continha mais anunciantes e quase no final da circulação diminuiu, página 2, edição 3, 1936 e terceira capa, edição 32, 1939 respectivamente.

Fonte: Elaborado pelo autor, com base na pesquisa realizada.

\subsection{Desenvolvimento dos anúncios}

Ao longo das edições, foi observado que alguns anúncios foram publicados em apenas uma edição, ou era a mesma composição gráfica do início ao fim do período em que estava presente, porém diversos anúncios tiveram um crescimento em sua construção gráfica, com aumento de recursos que abarcavam a inclusão de imagens, variação da composição com as tipografias e a disposição das mesmas, e também variação no uso de ilustrações.

Um anunciante que apresentou mudanças marcantes foi a Casa Beraldo. Uma alfaiataria que nas primeiras publicações possuía anúncio composto apenas por lettering, e após algumas edições foram incluídas ilustração e caligrafia. Nessa segunda configuração, os elementos foram construídos de forma orgânica, com texto contraposto na imagem e com o adicional do endereço do alfaiate. Por fim, sua composição ficou mais limpa e sua imagem mais refinada, com ilustração de um homem com terno e o nome do estabelecimento abaixo em tipografia sem serifa. 

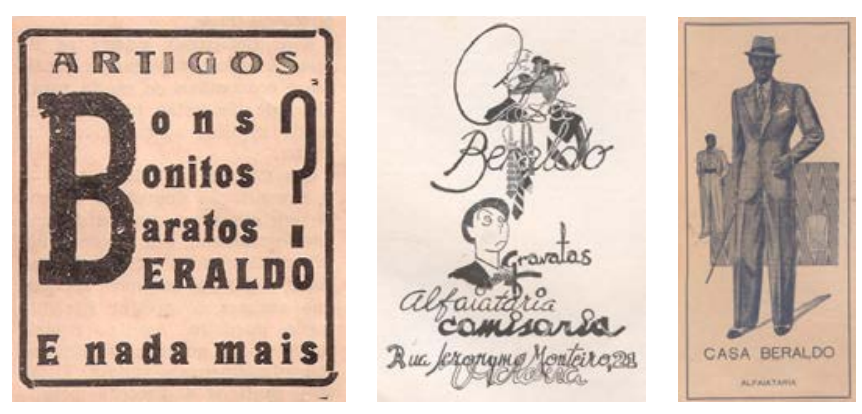

Figura 21, 22 e 23 - Imagens do anunciante Beraldo que teve uma evolução na sua composição gráfica ao decorrer da circulação da Chanaan, página 49, edição 04, 1936, página 19, edição 20, 1937 e página 69 , edição 27,1938 respectivamente.

Fonte: Elaborado pelo autor, com base na pesquisa realizada.

Houve ainda anúncios que realizaram apenas uma mudança na composição e continuou sendo publicado dessa última forma até o final da revista, como é o caso do anunciante Banco do Brasil.

Nas primeiras edições em que foi anunciada a Drogaria Popular, a anunciante tinha em cada anúncio uma ilustração diferente, porém após a oitava edição fixou sua propaganda apenas uma ilustração, indo até o fim da circulação da revista.

Diferente dos anúncios que, apesar das mudanças chegaram em um formato final, existiram anúncios que mudavam de formato e continuavam assim em uma média de cinco edições, mudavam de novo e novamente eram publicados diferentes. O Elixir de Inhame e de Nogueira tinham essa característica.

Emulsão de Scott teve um anúncio diferente para cada edição em que era publicado, usando sempre como recurso tipografia, lettering e ilustração.

Outro aspecto de produção observado, é de uma mesma composição ser feita para anunciar dois anunciantes diferentes, como o da casa Mayrink, uma casa de instalação de eletricidade, e de uma das composições do anunciante Externato Julia Penna, que também possuiu outros tipos diferentes de composição.
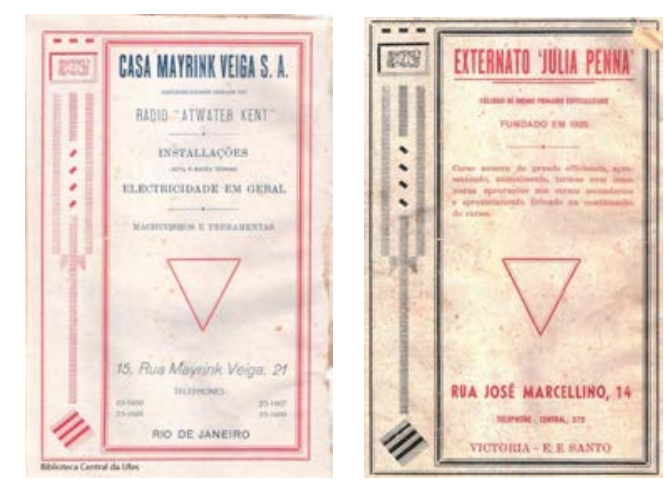

Figuras 24 e 25 - Anúncios de anunciantes diferentes, porém com a mesma composição gráfica, quarta página, edição 1, 1936 e quarta página, edição 2, 1936 respectivamente.

Fonte: Elaborado pelo autor, com base na pesquisa realizada.

\subsection{Fim da revista}

Percebeu-se que a periodicidade das últimas edições da revista Chanaan foi alterada, pois havia maior espaço de tempo entre uma edição e outra. Simultaneamente a esse período, foi constatada uma decadência em alguns aspectos 
da revista, como menor número de páginas, aumento do uso de papel poroso e queda na utilização de imagens. Supõe-se que o investimento diminuiu na medida em que o número de anunciantes estava reduzido.

Coincidentemente, em novembro de 1939, houve um incêndio na Imprensa Oficial do Espírito Santo, parque gráfico que imprimia a revista, o que provocou a perda e destruição de quase todos os equipamentos e do acervo da instituição (Mattedi, 2005).

O fim da publicação da Chanaan coincide com o citado incêndio, atribuindo-se a esses fatores os possíveis motivos pelos quais a revista encerrou sua trajetória.

\section{CONCLUSÃO}

Os resultados da presente pesquisa mostram que, além do ritmo de experimentações, a produção capixaba sob a ótica do design gráfico na década de 1930, contribuindo para os estudos relacionados à memória gráfica e comprovando a importância dos anúncios para a configuração gráfica da revista.

A popularidade da revista pode ser observada pela grande quantidade de anúncios nas edições e pela frequência dos anúncios de fora do estado, principalmente com os anunciantes nacionais, como os citados Colgate, Palmolive e Granado. O investimento no apelo visual era grande, mesmo nos anúncios tipográficos. Chamam atenção os experimentos com tipografia e suas variações, 0 frequente uso de lettering e caligrafia, o uso de bordas ornamentadas e bordas com composições de fios simples.

Nos anúncios imagéticos a variação de ilustrações pictóricas era recorrente, apresentando ainda uso de fotografia e quadrinhos, demonstrando cuidado para conquistar e convencer a compra dos possíveis clientes. Os anúncios considerados híbridos, por ter imagem e um longo texto, sempre vinham com um texto explicando o produto, sendo uma outra forma de atrair o público.

Foi possível observar o crescimento de alguns anunciantes, que iniciaram a publicação de seus anúncios apenas com uso de tipografia e que depois passaram a investir na produção de anúncios imagéticos.

Através do levantamento do acervo, coleta de dados e análises gráficas dos anúncios da revista Chanaan foi possível reconhecer recursos gráficos com um repertório que é reflexo do seu tempo, mostrando que é uma rica fonte de recursos visuais em composição. Espera-se colaborar na construção de um material de consulta e contribuir para a construção da memória gráfica capixaba.

\section{REFERÊNCIAS}

ACHIAMÉ, Fernando. O Espírito Santo na Era Vargas (1930-1937): Elites políticas e reformismo autoritário. Vitória - ES: FGV, 2010.

BRINGHURST, Robert. Elementos do estilo tipográfico (versão 3.0). São Paulo: Cosac Naify, 2005.

CHANAAN. Espírito Santo: Imprensa Official. 1936 - 1939. Mensal.

DUTRA, Thiago Luiz Mendes; Fonseca, Letícia Pedruzzi. Metodologia de análise gráfica do Jornal Posição: otimização de processos em pesquisas relacionadas à 
memória. In: 60 Congresso Nacional de Iniciação Científica em Design da Informação. Pernambuco: Blucher, 2013.

FINIZOLA, Fátima. Tipografia vernacular urbana: uma análise dos letreiramentos populares (coleção pensando o design). São Paulo: Blucher, 2010.

LESCHKO, Nadia Miranda. Tradição gráfica em Pelotas: Estudo de mapeamento da indústria gráfica com base nos anúncios publicados no Álbum de Pelotas $1922 \mathrm{e}$ Almanach de Pelotas 1920-1929. In: 4 Seminário Internacional em Memória e Patrimônio. Pelotas: Ed. da UFPel, 2010.

MATTEDI, José Carlos. História da Impresa Oficial do Espírito Santo. Vitória - ES: [s.n.], 2005.

TONINI, Juliana; et all. Desenvolvimento da Ficha de coleta de dados para análise gráfica da revista Vida Capichaba. In: 9o Congresso Brasileiro de Pesquisa e Desenvolvimento em Design. São Paulo: Blucher, 2010.

VILLAS-BOAS, André. Produção gráfica para designers. Rio de Janeiro: 2AB, 2008. 